DOCTRINA

\title{
Las acciones civiles por infracciones al derecho de propiedad intelectual
}

\author{
Private law remedies for the infringement of intellectual property rights
}

\author{
Alberto Pino Emhart (iD \\ Universidad Adolfo Ibáñez, Chile
}

\begin{abstract}
RESUMEN El artículo analiza las acciones civiles contempladas por la Ley chilena de Propiedad Intelectual para la protección de los derechos de autor y derechos conexos, examinando la reparación en naturaleza, las acciones indemnizatorias, la acción de licencias o regalías hipotéticas y la acción restitutoria de ganancias ilícitas. Dada la reciente incorporación a la legislación chilena de algunas de estas acciones y los escasos estudios doctrinales -en especial sobre la reparación en naturaleza y las acciones restitutorias-, se discuten sus requisitos de procedencia y eventuales posibilidades de acumulación. Ello con el objetivo de otorgar herramientas para evaluar la eficacia de estos mecanismos para la protección de los derechos.
\end{abstract}

PALABRAS CLAVE Acciones civiles, propiedad intelectual, derechos de autor, licencias hipotéticas, restitución de ganancias ilícitas.

ABTRACT The article analyzes the private law remedies established by the Chilean statute of Intellectual Property, for the protection of copyrights, reviewing the injunctions, compensatory damages, restitutionary damages or royalty fees, and disgorgement of profits. Given the recent incorporation of these remedies into Chilean Law, and the few scholarly studies on the subject (especially on injunctions and restitutionary damages), the article discusses the requirements of each of these remedies, and explores the possibility of accumulating the remedies. The overall objective is to provide information to assess the efficacy of these mechanisms for the protection of copyrights.

KEYWORDS Remedies, intellectual property, Copyright Law, royalty fees, disgorgement of profits. 


\section{Introducción}

La protección de la propiedad privada sobre bienes intelectuales es una preocupación relativamente reciente en el derecho. ${ }^{1}$ La famosa frase del Código Civil chileno en su artículo 583, según la cual sobre las cosas incorporales «hay también una especie de propiedad», refleja la incomodidad de asimilar la tradicional regulación sobre las cosas incorporales también al ámbito de las cosas corporales. ${ }^{2} \mathrm{Y}$ es lógico que ello sea así. La justificación de la propiedad privada sobre bienes corporales es distinta que la justificación de la propiedad privada sobre bienes incorporales, y ello tiene implicancias respecto de la forma en que el derecho protege estos bienes.

Como señala de manera acertada Waldron (1996: 4), en un sentido constituye una tarea más sencilla justificar la propiedad privada sobre bienes intelectuales que sobre la tierra, toda vez que los bienes intelectuales son creaciones individuales, mientras que la tierra no ha sido creada por su dueño, sino que viene dada por la naturaleza. Al tratarse de bienes intelectuales, resulta más obvia una justificación como la planteada por Locke en relación con el valor que incorpora el dueño al objeto de su propiedad. Sin embargo, a la inversa, también puede indicarse que los bienes intelectuales parecen no necesitar la misma regulación que los bienes corporales, ya que los primeros permiten ser utilizados en forma simultánea por distintos usuarios. Se trata de bienes no excluyentes en su uso: mientras que tan solo un sujeto puede usar una silla, miles o millones pueden escuchar una canción o leer una novela.

A partir de este contraste, resulta interesante analizar las acciones civiles o remedios judiciales ${ }^{3}$ que provee el sistema jurídico frente a la vulneración del derecho de autor. ${ }^{4} \mathrm{~A}$ este respecto, podemos preguntarnos en primer lugar: ¿merece la propiedad intelectual un tratamiento distinto que la propiedad sobre bienes corporales? Y si la respuesta es afirmativa, ¿en qué consistiría este sistema especial de acciones o remedios? El asunto resulta apremiante para la determinación del carácter absoluto que tiene el derecho de propiedad, en el sentido de cuestionarnos seriamente qué tan

1. Un panorama general de la evolución del derecho de autor en América Latina puede encontrarse en Cerda Silva (2016), artículo en que se da cuenta de su desarrollo durante el siglo XIX.

2. Un agudo análisis sobre esta expresión del artículo 583 en Guzmán Brito (1995: 119-152).

3. Utilizaré indistintamente estos términos a lo largo del trabajo, aunque en un sentido técnico no son del todo equivalentes, pues el concepto de remedios es más específico y propio del ámbito del derecho privado que la noción jurídica más amplia de acciones. Siguiendo a Burrows (2007: 1.617-1.618), entiendo por remedio judicial la satisfacción que puede obtener un individuo recurriendo a un tribunal a partir de una causa de acción (en general, un incumplimiento de contrato, un ilícito civil o un enriquecimiento injustificado). En este caso, la causa de acción de los remedios se configura por la infracción a un derecho de propiedad intelectual.

4. Se excluyen del presente estudio las acciones penales que pueden originarse a partir de infracciones al derecho de propiedad intelectual y las medidas precautorias que contempla la Ley de Propiedad Intelectual en su artículo 85.D. Sobre esto último, véase Walker (2014: 322-323). 
absoluto debería ser el derecho de propiedad sobre estos bienes, al tomar en cuenta el atributo de exclusividad que otorga el derecho de propiedad a su titular, que le otorga un monopolio sobre el uso de estos recursos (Contreras-Jaramillo, 2017: 99-130), teniendo en cuenta además que la ley pone a disposición del titular de los derechos de propiedad intelectual medidas de carácter coercitivo, como la destrucción o incautación de ciertos bienes.

En este contexto, el objeto de análisis del presente artículo serán las diferentes acciones o remedios contemplados por el legislador civil chileno en la Ley 17.336 de Propiedad Intelectual, entre sus artículos 85.B y 85.E. Como veremos, el legislador contempla un abanico de acciones que van desde la reparación en naturaleza mediante órdenes judiciales, pasando por las acciones indemnizatorias, una acción restitutoria de licencias hipotéticas, e incluso una acción restitutoria por las ganancias obtenidas por el infractor. Esta última hipótesis en especial será analizada, dado lo novedoso que resulta la figura para el derecho chileno y el escaso estudio sobre ella, ${ }^{5}$ a diferencia del interés que estas hipótesis generan en otros sistemas jurídicos. ${ }^{6}$ Para ello, el artículo analiza en primer lugar el esquema general de remedios enunciado por el legislador chileno en el artículo 85.B, para luego analizar cada una de estas acciones en detalle, con particular énfasis en la acción restitutoria del artículo 85.E. El análisis de los textos legales chilenos se enriquecerá con algunos aportes del derecho comparado, ya que se trata de una materia armonizada a través de los diversos tratados internacionales (Strömholm, 1990: 3-183). Además, para el análisis se tendrán en cuenta las reglas generales sobre la responsabilidad civil en Chile. El estudio no se centra de manera directa en la jurisprudencia de los tribunales chilenos, debido a que se trata de normas relativamente nuevas, sin perjuicio de que se mencionen algunas sentencias de relevancia sobre algunos puntos. Por último, se enuncian las principales conclusiones del trabajo.

\section{Sistema de acciones civiles de la Ley de Propiedad Intelectual: Derecho de opción del titular de los derechos}

Los remedios judiciales frente a la vulneración de derechos de propiedad intelectual tienen una peculiar configuración desde el punto de vista del derecho civil en general. Por una parte, de cierto modo se trata de hipótesis de responsabilidad civil, que puede ser de naturaleza contractual o extracontractual (Walker Echenique, 2014:

5. Con la excepción de los trabajos de Barría (2017a: 177-213; 2017b: 399-418).

6. Así, por ejemplo, de acuerdo con Englard (2007: 255) «mientras que en la literatura jurídica alemana el tema de la restitución de ganancias constituye un tópico favorito que ha recibido mucha atención por los juristas, el asunto es apenas mencionado en la mayoría de los otros sistemas, especialmente en los países latinos». 
309). Ello, naturalmente, trae aparejado como mecanismo de reparación la acción indemnizatoria de los daños sufridos por el titular del derecho de propiedad intelectual, según las reglas generales de la responsabilidad civil. En términos de Calabresi y Melamed (1996), estaríamos en presencia de una regla de responsabilidad. Sin embargo, debemos recordar que el derecho infringido corresponde a un derecho de propiedad, con lo cual resulta necesario considerar también acciones que permitan obtener una reparación en naturaleza del derecho infringido y acciones restitutorias, específicamente la restitución de las ganancias obtenidas de manera ilícita por el infractor.

En este sentido, el artículo 85.B establece claramente un catálogo de acciones civiles a favor del titular de los derechos de propiedad intelectual infringidos, al señalar que:?

El titular de los derechos reconocidos en esta ley tendrá, sin perjuicio de las otras acciones que le correspondan, acciones para pedir:

a) El cese de la actividad ilícita del infractor.

b) La indemnización de los daños y perjuicios patrimoniales y morales causados.

c) La publicación de un extracto de la sentencia, a costa del demandado, mediante anuncio en un diario de circulación comercial de la región correspondiente, a elección del perjudicado.

Podemos apreciar que la ley pone a disposición del titular del derecho infringido un abanico de acciones para la satisfacción de su interés, de manera similar como lo plantean los instrumentos supranacionales para el derecho contractual, ${ }^{8}$ así como la mayor parte de la doctrina actual chilena. ${ }^{9} \mathrm{Al}$ igual que el acreedor dentro del derecho moderno de los contratos, el titular de los derechos de propiedad intelectual puede elegir de forma libre por ejercer estas acciones, siempre que se cumplan cada uno de sus requisitos. De inmediato podemos descartar la existencia de una jerarquía u orden de prelación entre estas acciones, por lo que el titular de los derechos debiese tener absoluta libertad para elegir entre las distintas acciones ofrecidas por el legislador, sin que exista entre ellas jerarquía alguna, como tradicionalmente se solía sostener en el ámbito del derecho contractual chileno.

De lo anterior se desprende que el titular de los derechos vulnerados no está obligado a solicitar una indemnización de perjuicios para hacer valer sus derechos frente

7. De modo similar, el artículo 106 de la Ley de Propiedad Industrial (Ley 19.039) establece un catálogo de acciones a favor del titular de los derechos de propiedad industrial infringidos, a su elección. Sobre esto, véase Morales Andrade (2006) y Pino Emhart (2019).

8. Véase por ejemplo los artículos 45 y 61 de la Convención de las Naciones Unidas sobre los contratos de compraventa internacional de mercaderías (CISG), o el artículo 8:101 de los Principios Europeos de Derechos de los Contratos (PECL).

9. Dentro de la literatura más reciente, véase Cárdenas Villarreal y Reveco Urzúa (2018), y De la Maza Gazmuri y Vidal Olivares (2018). 
a la infracción, pues es posible que solo solicite la reparación en naturaleza (por ejemplo, el cese de la actividad ilícita del infractor).$^{10}$ De manera novedosa, ello permite configurar una hipótesis de responsabilidad civil que prescinde de la existencia de un daño resarcible como requisito necesario para su ejercicio, y cuyo objeto será una reparación in natura de los derechos, la que se concreta mediante una orden judicial. ${ }^{11}$ Esto se justifica por cuanto es posible que para el titular de los derechos no sea atractiva la opción de la indemnización de perjuicios, sino la reparación en naturaleza. Sería la situación, por ejemplo, de un músico que, insatisfecho con la obra musical que ha grabado, le indica en forma expresa a su compañía discográfica no publicar el material. Incumpliendo esta indicación, la compañía discográfica divulga el material. Si bien el músico tiene la opción de demandar, en específico por el daño moral de autor (contemplado por la Ley en su artículo 14 numeral 3), es plausible pensar que la opción más atractiva en este caso para el autor sea solicitar el cese de la divulgación del material que se quería mantener inédito, y no por necesidad la indemnización de perjuicios. ${ }^{12}$

Continuando con la comparación de este sistema de acciones con el ámbito contractual, puede afirmarse que el ejercicio conjunto o acumulativo de las acciones civiles para la protección de la propiedad intelectual no resulta problemático, con lo cual no se ve obstáculo alguno para que el titular de los derechos pueda solicitar la reparación en naturaleza - por ejemplo, el cese de la actividad ilícita del infractor del literal a)—, y además la indemnización de los perjuicios causados del literal b) y la publicación de un extracto de la sentencia. Ello, a diferencia de lo que ocurre en el ámbito de los remedios contractuales, en el cual las acciones no siempre son acumulativas. ${ }^{13}$ Como destaca Epstein (2018: 50), es deseable la configuración de estos remedios de forma complementaria y no alternativa, ya que la sola acción indemnizatoria no impide que el demandado siga cometiendo en el futuro las infracciones reclamadas por el titular de los derechos. Ello solo puede lograrse mediante una orden judicial.

10. En el mismo sentido, Barros Bourie (2006: 878): «La reparación en naturaleza es una opción para el demandante, pues el derecho chileno no establece un orden de precedencia de las acciones» (énfasis en el original).

11. Ello incluso en el evento de entender que la sola infracción del derecho de autor genera un daño para el titular del derecho, como se sostiene en Walker Echenique (2014: 318), ya que no necesariamente se trataría de un daño indemnizable o resarcible. Agradezco esta aguda observación de un revisor anónimo.

12. En tal evento, podría cobrar especial importancia una eventual condena en costas del infractor vencido en juicio, según la regla general del artículo 144 del Código de Procedimiento Civil —a menos que haya tenido motivo plausible para litigar-, lo que sí podría significar un desembolso de dinero significativo por parte del demandado.

13. Por ejemplo, el ejercicio de la acción resolutoria es incompatible con el cumplimiento forzado del contrato o con la acción indemnizatoria sustitutiva de la prestación. 


\section{Las acciones de reparación en naturaleza}

Como ya hemos visto, la reparación en naturaleza de la infracción del derecho de propiedad intelectual puede ser de vital importancia para el titular del derecho vulnerado, pues el objetivo principal es el cese de la actividad ilícita del infractor. Como señala Barros Bourie (2006: 877), «la acción para poner término al daño actual es la más elemental de las acciones que persiguen la restitución en naturaleza, y el juez está autorizado para decretar la suspensión del hecho ilícito que provoca la turbación del derecho o interés perturbado». Así también lo dispone la Directiva Europea 2004/48/ CE en su artículo 11, el cual dispone que los Estados miembros deben garantizar que «cuando se haya adoptado una decisión judicial al constatar una infracción de un derecho de propiedad intelectual, las autoridades judiciales puedan dictar contra el infractor un mandamiento judicial destinado a impedir la continuación de dicha infracción». ${ }^{14}$ Sin embargo, al igual que el cumplimiento forzado del contrato (Bahamondes Oyarzún, 2018: 804), las órdenes judiciales pueden ser opresivas y contrarias al interés público (Barros Bourie, 2006: 879), por lo cual deben ser analizadas en detalle. Ello resulta apremiante debido a que la legislación procesal chilena carece de una regulación sistemática general de la reparación civil en naturaleza.

Las normas especiales que establece la Ley de Propiedad Intelectual se encuentran contenidas en los artículos 85.B, 85.C y 85.F, normas que permiten solicitar las siguientes medidas de reparación en naturaleza: el cese de la actividad ilícita del infractor (artículo 85 letra a), la publicación de un extracto de la sentencia (artículo 85.B letra c), la destrucción o apartación del comercio de los ejemplares que hubieren sido producto de alguna infracción a la Ley (artículo 85.C), y la incautación y entrega al titular del producto de la recitación, representación, reproducción, ejecución o cualquier otra forma de explotación ilícita, sin perjuicio de los derechos que puedan hacer valer terceros (artículo 85.F). Estas son las medidas de carácter definitivo contempladas por la Ley, mientras que se excluyen de este estudio las medidas precautorias que la ley autoriza al juez a decretar en cualquier estado del juicio (85.D).

Si bien se trata de una materia respecto de la cual hay menos armonización, se advierte una tendencia a establecer estas medidas con algún grado de discrecionalidad para los jueces, debido al carácter opresivo que pueden tener, como se advirtió más arriba. En el derecho anglosajón, ello se manifiesta en el estatuto que regula estas medidas (injunctions), gobernadas por el régimen de equity y que otorga a los tribunales discrecionalidad al momento de decretarlas (Speck y otros, 2018: 1.208). ${ }^{15}$

\footnotetext{
14. «Directiva 2004/48/CE del Parlamento Europeo y del Consejo», Diario Oficial de la Unión Europea, en Boletín Oficial del Estado, 29 de abril de 2004, disponible en https://bit.ly/35d31n8.

15. En el derecho norteamericano incluso se consideran como medidas extraordinarias o excepcionales, sometidas a requisitos estrictos (Ross, 2018: 683).
} 
En cambio, para el derecho continental las acciones de reparación en naturaleza son consideradas como remedios normales frente a la infracción de derechos de propiedad intelectual, aunque estas órdenes pueden ser denegadas en aquellos casos en los cuales la medida sea desproporcionada, considerando el daño causado al infractor y el beneficio que de ello deriva para el titular de las acciones (Sikorski, 2019: 34). Este límite se desprende a su vez de los principios generales contemplados por la Directiva Europea 2004/48/CE en su artículo 3, conforme al cual las medidas, procedimientos y recursos para la protección de la propiedad intelectual deben ser efectivos, proporcionados y disuasorios. Así, por ejemplo, la Ley de Propiedad Intelectual de España (Real Decreto Legislativo 1/1996) contempla de forma expresa en su artículo 138 que las medidas judiciales deben «ser objetivas, proporcionadas y no discriminatorias».

De manera interesante, la Directiva Europea 2004/48/CE establece en su artículo 12 que los Estados miembros pueden contemplar en su legislación acciones indemnizatorias que reemplazan a las órdenes judiciales en caso de que el tribunal las considere desproporcionadas. Ello proviene del derecho alemán (Sikorski, 2019: 36) y también se contempla en el derecho inglés (damages in lieu of an injunction) (Speck y otros, 2018: 1.213).

A falta de una regulación expresa al respecto en Chile, sería deseable de lege ferenda que la legislación pudiera adecuarse a estas restricciones, otorgándole mayor flexibilidad a los tribunales para decretar estas medidas. Mientras ello no ocurra, los tribunales deberían decretar estas medidas frente a una infracción sin mayores obstáculos, sin perjuicio de las restricciones propias del derecho común que podrían considerarse, como la del abuso del derecho o incluso la buena fe.

\section{La cesación de la actividad ilícita (artículo 85.B letra a)}

Siguiendo el orden establecido por la Ley de Propiedad Intelectual, iniciaremos el análisis con el cese de la actividad ilícita de los infractores, contemplado en el artículo 85.B letra a). Bajo una estructura similar a la de la Ley, la legislación española -la cual es seguida de cerca por la chilena-contempla una regulación más completa al respecto, pues señala en el artículo 139 numeral 1 de la Ley de Propiedad Intelectual que «el cese de la actividad ilícita podrá comprender: a) la suspensión de la explotación o actividad infractora», $\mathrm{y}$ «la prohibición al infractor de reanudar la explotación o actividad infractora». Se distinguen por consiguiente dos tipos de medidas: una destinada a hacer cesar una actividad del infractor que continúa al momento que el titular ejerce la acción, y la otra que atiende al futuro, al establecer una prohibición para el infractor de desarrollar una actividad. Aunque la ley chilena omite contemplar esta distinción, en principio no habría inconveniente en que el juez decrete ambas, puesto que no tendría sentido que el tribunal decrete el cese de una actividad sin disponer orden alguna para el futuro. Como de manera acertada señala Armengot 
Vilaplana (2003: 287), «las infracciones a los derechos de propiedad intelectual no se consuman en unidad de acto, sino que presentan una clara tendencia a la reiteración». De modo tal que una simple orden de cesación de la actividad ilícita sería poco efectiva, por lo que es necesaria en consecuencia una prohibición adicional hacia el futuro. Esta prohibición hacia el futuro también tiene asidero en la ley chilena, al considerar las medidas cautelares contempladas en el artículo 85.D letra d), en la que se permite solicitar la retención de materiales, maquinarias e implementos que hayan sido destinados a la producción de ejemplares ilícitos, "cuando ello sea necesario para prevenir futuras infracciones». Similar perspectiva se desprende de la medida contemplada en la letra e) del mismo artículo.

La doctrina española señala que la acción tiene un carácter real, «en cuanto derivada de la titularidad de un derecho absoluto, la propiedad intelectual» (Carrasco Perera, 2007a: 1.673). Esta caracterización debiese ser también aplicable al derecho chileno. De ello se desprende que el ejercicio de la acción no dependa de la existencia ni prueba de un daño resarcible para el titular de los derechos, ni tampoco se requiere acreditar negligencia o dolo por parte del infractor. Así las cosas, si la infracción a la propiedad intelectual es cometida de manera inocente, ello no obsta a que el titular de los derechos pueda solicitar el cese de la actividad ilícita, pues la culpa o dolo solo es requisito de la acción indemnizatoria.

Como apunta Armengot Vilaplana (2003: 291-292), para que se decrete una prohibición judicial hacia el futuro, con el objetivo que el infractor no incurra de nuevo en las actividades que dan lugar a la infracción de los derechos infringidos, no basta solo con que se haya cometido una infracción, sino que también es requisito que exista un peligro de repetición en el futuro de la actividad ilícita. Es por ello que, si la actividad del sujeto infractor ha cesado, el titular de los derechos no podrá solicitar esta medida, por lo que deberá necesariamente recurrir a la acción indemnizatoria para satisfacer su interés.

\section{La destrucción o apartación del comercio de los ejemplares}

La explotación de los derechos de propiedad intelectual usualmente se traduce en la producción de determinados resultados materiales, y la utilización de determinadas maquinarias o aparatos para la producción del material ilícito. El artículo 85.C contempla la posibilidad para el titular de los derechos la destrucción o apartación del comercio de «los ejemplares que hubieren sido producto de alguna infracción». Siguiendo a Carrasco Perera (2007a: 1.675), el concepto de ejemplar en esta norma - misma expresión utilizada por el artículo 139 de la ley española- debiera interpretarse en un sentido amplio, cubriendo en definitiva «cualquier resultado tangible de una explotación usurpatoria», independiente de la forma específica que adopte la infracción (registro audiovisual, gráfico, fotográfico, sonoro, etcétera). 
Por otra parte, la norma omite referirse a los materiales, maquinarias e implementos que hayan sido destinados a la producción de ejemplares ilícitos o de la actividad infractora, a los cuales la ley alude a propósito de las medidas cautelares que el titular de los derechos puede solicitar durante el transcurso del juicio (artículo 85.D letra d). Ello resulta curioso, puesto que si bien el demandante podrá solicitar como medida cautelar la retención o secuestro de estos materiales, la ley nada dice respecto de lo que ocurriría una vez que se dicta la sentencia condenatoria en contra del infractor. Ante el silencio del legislador, debiéramos concluir que el tribunal no estaría facultado para ordenar su destrucción, puesto que el artículo 85.C restringe esta orden a los «ejemplares». A diferencia de lo que ocurre con «los aparatos que hayan sido utilizados en la comunicación pública no autorizada», los cuales pueden ser removidos o retirados, a menos que «el presunto infractor garantice que no reanudará la actividad infractora» (artículo 85.D letra e). Se trata aquí de una medida cautelar, pero que tendrá un efecto definitivo sobre estos bienes.

La norma establece que el tribunal decretará esta orden a solicitud del perjudicado, y que los ejemplares solo podrán ser destinados a beneficencia si cuenta con autorización del titular de los derechos. La norma parece tener un carácter imperativo para el tribunal, al señalar que la orden será decretada a solicitud del perjudicado. Como ya se ha advertido antes, estas medidas en el derecho comparado suelen aplicarse con algún grado de flexibilidad, lo que de algún modo puede apreciarse en la medida cautelar del artículo 85.D letra e) recién comentada. Pero por cierto que la orden de destrucción o apartación del comercio de los ejemplares puede ser una medida coercitiva, sobre todo en situaciones en las cuales el ejemplar contiene tan solo en parte un contenido que infringe los derechos de propiedad intelectual. Por ejemplo, supongamos un libro de 300 fotografías, de las cuales una vulnera derechos de propiedad intelectual. En un caso como éste, la destrucción o apartación del comercio de 200 ejemplares será una medida desproporcionada para el infractor, pudiéndose eventualmente satisfacer al titular de los derechos mediante la indemnización de perjuicios o removiendo la parte del ejemplar que constituye la infracción —en caso de que ello sea posible-. Es por ello que, aunque la ley no lo establezca en forma expresa, los tribunales debieran aplicar esta medida con algún grado de flexibilidad.

\section{La publicación de un extracto de la sentencia y la tutela meramente declarativa}

El artículo 85.B letra c) establece una tercera posibilidad para el titular de los derechos, que consiste en solicitar la «publicación de un extracto de la sentencia, a costa del demandado, mediante anuncio en un diario de circulación comercial de la región correspondiente, a elección del perjudicado». Se trata de un mecanismo de reparación en naturaleza contemplado con frecuencia por los ordenamientos jurídicos en 
casos de lesión al honor o intimidad personal. ${ }^{16}$ La pregunta que cabe plantearse aquí es si el titular de los derechos podría exigir esta tutela, con el solo objetivo de reivindicar sus derechos, sin solicitar cese alguno de la actividad ilícita ni tampoco una indemnización de perjuicios. La respuesta a esta pregunta depende por cierto de si pueden admitirse en el sistema chileno las tutelas meramente declarativas, ante lo cual la respuesta de la doctrina chilena es afirmativa, condicionada a la concurrencia de algunos requisitos (Rivero Hurtado, 2019: 97). En este caso, será relevante que exista incertidumbre jurídica o falta de certeza sobre la existencia, alcance o modalidad de los derechos de propiedad intelectual, y la existencia de un interés que justifique la tutela meramente declarativa. Como señala Armengot Vilaplana (2003: 277-278), este interés que justifique la tutela declarativa puede consistir en, por ejemplo, el hecho de que un tercero se atribuya de manera inadecuada la autoría de una obra, o en que se haya desconocido la titularidad del derecho moral de autor. En estas circunstancias, debiera ser posible para el titular de los derechos ejercer una tutela declarativa y solicitar la publicación del extracto de la sentencia condenatoria, con independencia de si se hubiere o no solicitado otros remedios.

\section{La acción indemnizatoria}

La acción indemnizatoria es una sola, y se encuentra contemplada por los artículos 85.A, 85.B letra b) y 85.E. Para estos efectos, abordaré en forma separada la indemnización del daño patrimonial y del daño moral.

\section{Indemnización de daños patrimoniales}

El artículo 85.A de la Ley de Propiedad Intelectual señala que el monto de los perjuicios «se determinará en base al valor legítimo de venta al detalle de los objetos protegidos», y luego agrega que si se trata de objetos que no tienen valor de venta legítimo, el juez fijará prudencialmente su monto. Como veremos más adelante, se trata de la figura de las licencias o regalías hipotéticas. Era necesario que la ley indicara que se trata del valor de venta legítimo, puesto que el objetivo es considerar el valor real de los bienes protegidos, y no el valor que podría obtenerse como consecuencia de su venta ilegal o mediante falsificaciones. De manera un tanto confusa, el artículo 85.E dispone que «el tribunal considerará, entre otros factores, el valor legítimo de venta al detalle de los bienes sobre los cuales recae la infracción». Una interpretación posible sería que el artículo 85.A se refiere a la indemnización de perjuicios en general, mientras que el artículo 85.E se refiere más en específico a los daños patrimoniales. Sin embargo, no

16. De modo general, véase el artículo 1.740 del Código Civil y Comercial de Argentina, de 2014. En Chile, véase el artículo 42 de la Ley 19.733, de 2001. 
parece razonable aplicar la norma del artículo 85.A a los daños morales, ya que a ellos se refiere el inciso segundo del artículo 85.E, y otorga directrices para su avaluación que no tienen que ver con el valor de venta. Por consiguiente, lo más razonable sería concluir que el legislador quiso en el artículo 85.E dejar abierta la posibilidad para el titular de los derechos de reclamar la indemnización de los perjuicios por lucro cesante efectivamente sufridos, con prescindencia del criterio de la licencia hipotética. La norma señala que el tribunal es quien hará la determinación, pero dicha avaluación será cumplida según los antecedentes aportados por el demandante en el proceso.

Las licencias o regalías hipotéticas consisten en un mecanismo mediante el cual el titular de un derecho que ha sido infringido solicita al tribunal que el demandado pague un valor que represente el monto que éste habría tenido que pagar al demandante si hubiese solicitado autorización antes de infringir el derecho. La fórmula se configura por la elaboración implícita de un acuerdo contractual de carácter hipotético, puesto que la negociación real nunca tuvo lugar (Hedley, 2000: 242). El monto para pagar por el demandado corresponderá al precio de mercado asignado al bien o derecho infringido, ya que se trata de reestablecer lo que habría ocurrido si el demandado hubiese actuado conforme al cauce jurídico adecuado desde un comienzo. Ello con independencia de los beneficios que haya obtenido el demandado como consecuencia de la utilización del bien, y los daños que eventualmente se hayan causado al titular del derecho. El mecanismo recibe distintos nombres en la literatura jurídica, entre los cuales los más conocidos son los de «regalías» $\mathrm{y}$ «licencias hipotéticas», aunque también se le ha denominado en ocasiones como «demanda por uso» (Jaffey, 2000: 151) o «daños por pérdida de la oportunidad de negociar» (Sharpe y Waddams, 1982) y más recientemente como «daños de negociación». ${ }^{17}$ La designación del nombre es relevante, puesto que ello tendrá implicancias en la determinación de la naturaleza jurídica de la tutela, que puede calificarse de indemnizatoria o restitutoria. Se utilizará en este trabajo la denominación neutral de «licencias hipotéticas».

Existe un arduo debate sobre la naturaleza jurídica de las licencias hipotéticas en el derecho alemán y anglosajón (Jaffey, 2011). Algunos sostienen que la naturaleza jurídica es indemnizatoria, bajo la perspectiva de que el monto es un mecanismo o fórmula de cálculo para determinar los daños sufridos por el titular del derecho en términos de lucro cesante. En este sentido, se ha señalado que las licencias hipotéticas representan el daño por una pérdida de la oportunidad para el titular del derecho de haber negociado la autorización correspondiente (Sharpe y Waddams, 1982). El monto de la licencia, por tanto, compensaría lo que el demandante dejó de percibir como consecuencia de no haberse solicitado la autorización previa. Esta postura tiene respaldo en la actualidad en el derecho inglés en una sentencia reciente de la Corte Suprema (caso Morris-Garner). Sin embargo, otra parte de la doctrina critica esta

17. Caso Morris-Garner con One Step (Support) Ltd, Corte Suprema del Reino Unido, 2018. 
interpretación, sosteniendo que se trata de un remedio restitutorio (Edelman, 2010). El principal argumento se basa en el hecho de que la licencia sería hipotética no solo porque reconstruiría una transacción que nunca ocurrió, sino que además una transacción que nunca podría haber ocurrido, en aquellos casos en los cuales el titular del derecho nunca habría aceptado autorizar al demandado (Burrows, 2008: 170).

Comentando una norma funcionalmente equivalente a la del artículo 85.A, Carrasco Perera (2007b: 1.692) sostiene que no tiene sentido discutir sobre la naturaleza jurídica de este remedio, dado que el tenor de la ley le otorga un carácter indemnizatorio, y la discusión no tendría consecuencia práctica alguna, al menos en este ámbito. Si bien es cierto que el tenor literal de la disposición se inclina por considerar el criterio de venta legítima como un método para el cálculo de la indemnización de perjuicios, en muchas ocasiones resultará artificioso concebirlo de esta forma, ya que el remedio operará independientemente de si el titular hubiese querido o incluso podido otorgar una licencia para el infractor (Basozabal Arrué, 1997: 1.274-1.275). Así ocurriría, por ejemplo, en caso de que el autor de una obra literaria la quiera mantener inédita, y una editorial la publique sin su autorización. En tal evento, el autor de la obra no sufre un daño propiamente hablando, pero ello no quita que la infracción a su derecho no merezca una respuesta del sistema jurídico, el cual se concreta en el otorgamiento de la licencia hipotética. En este sentido, la licencia hipotética representa por norma el hecho de que el demandado debería haber preguntado o pedido autorización primero al titular de los derechos antes de actuar.

Si estamos en lo correcto al calificar este mecanismo como restitutorio, la primera característica que salta a la vista es que el titular de los derechos no necesita acreditar la existencia de daños para ejercer esta acción, ni tampoco serán los daños la medida del remedio (Basozabal Arrué, 1998: 38-39). En efecto, en el ámbito de la propiedad intelectual se establece este remedio para liberar al titular de los derechos de la difícil prueba del lucro cesante (Barros Bourie, 2009: 38). En segundo lugar, las acciones restitutorias no suelen requerir grado alguno de imputación subjetiva del demandado, lo que es una de las principales diferencias respecto de las acciones indemnizatorias (Peñailillo Arévalo, 2003: 120). ${ }^{18}$ Ahora bien, en el ámbito de la propiedad intelectual, el remedio supone la infracción a un derecho de propiedad intelectual, lo cual nos llevaría a pensar que se requiere algún grado de culpa para que pueda ejercerse esta acción. El artículo 84 de la Ley de Propiedad Intelectual establece que incurre en responsabilidad civil quien «sabiendo o debiendo saber que inducirá, permitirá, facilitará u ocultará una infracción» de los derechos de autor o derechos conexos. Nótese que la norma señala que ello es requisito para incurrir en responsabilidad civil, por lo que podríamos sostener que la acción que persigue las licencias hipotéticas no sería una acción de responsabilidad civil y que, por lo tanto, no sería necesario imputarle

18. Restatement (Third) Restitution and Unjust Enrichment, American Law Institute, 2011, $₫ 53$. 
negligencia al infractor para solicitar una licencia hipotética, al igual que lo antes señalado respecto de la reparación en naturaleza. Así lo ha entendido la jurisprudencia alemana en el ámbito de la propiedad industrial, en la que se ha dejado de exigir culpa del demandado (Schlechtriem, 2007: 49).

Ahora bien, entendiendo que la acción es restitutoria, cabe plantearse la pregunta respecto de la concurrencia con una eventual acción indemnizatoria. Ya se ha señalado que la redacción del artículo 85.E permite entender que el juez determina los perjuicios patrimoniales sobre la base del valor legítimo de venta de los derechos, entre otros factores. Ello abriría la posibilidad de demandar perjuicios adicionales que no estuvieren incluidos en el valor de venta legítimo de los derechos (la licencia hipotética). Sin embargo, no sería razonable acumular en el monto a indemnizar daños correspondientes al lucro cesante. La razón de ello es que ambos mecanismos buscan reestablecer el mismo contenido del derecho de la víctima, con la licencia hipotética como un dispositivo de carácter alternativo y más efectivo que la acción indemnizatoria por lucro cesante. No obstante, ello no obsta a que las licencias hipotéticas se acumulen con una pretensión indemnizatoria de contenido distinto, por ejemplo, si la infracción genera un daño emergente o daño moral al titular de los derechos, ya que en estos casos el remedio indemnizatorio no coincide con el ámbito cubierto por la licencia hipotética (Carrasco Perera, 2007b: 1.695; Rubí Puig, 2015: 676-677).

La referencia al valor de venta legítimo del derecho debiera entenderse referida al precio de mercado del bien. ¿La referencia es al precio de mercado al momento de la infracción al derecho, al momento de la interposición de la demanda, o de la dictación de la sentencia? Dado que el remedio busca reestablecer la situación anterior a la comisión de la infracción al derecho, la conclusión debiese ser que se trata del precio de mercado al momento de la infracción. ${ }^{19}$ En cuanto a la valoración de la licencia, puede afirmarse que el punto de partida es que se trata de una valoración objetiva, por lo cual debe ser equivalente al valor del derecho infringido desde el punto de vista de una persona razonable que se encuentre en la posición del demandado (Lodder, 2012: 52). Por otra parte, el cálculo de la licencia hipotética prescinde de las ganancias o beneficios que haya obtenido con posterioridad el demandado, ya que no se restituyen de manera directa las ganancias. Me referiré más adelante a la restitución de ganancias, pero no corresponde confundirlo con la licencia hipotética, que no toma en cuenta los beneficios que haya obtenido con la explotación del bien protegido. ${ }^{20}$

19. En contra, Carrasco Perera (2007b: 1695), quien sugiere — siguiendo la jurisprudencia alemanaque el infractor debiese correr el riesgo de un aumento posterior del precio, por lo cual el valor correspondería al valor más alto entre la infracción y la dictación de la sentencia.

20. Es por ello que, a mi juicio, la Corte de Apelaciones de San Miguel, en sentencia rol 720-2011, del 22 de noviembre de 2011, se equivoca al tomar en cuenta los ingresos que el demandado efectivamente obtuvo con la ejecución de las obras para la determinación del monto de las licencias hipotéticas. 
Si bien el mecanismo de la licencia hipotética resulta conveniente para el titular de los derechos, por cuanto no necesita acreditar la existencia de daños, la doctrina ha considerado que el remedio es insuficiente para la completa protección de los derechos de propiedad intelectual (Carrasco Perera, 2007b: 1.793; Yzquierdo Tolsada y Arias Máiz, 2006: 135-140). Ello se debe a que la licencia hipotética se reduce a obligar al infractor a pagar el valor que habría tenido que pagar si hubiese solicitado antes autorización al titular de los derechos. Por consiguiente, resulta en la práctica indiferente para el infractor entre solicitar autorización ex ante, o solo cometer la infracción y pagar la licencia una vez condenado ex post. ${ }^{21}$ Por lo demás, la licencia hipotética tiene la consecuencia perniciosa de imponer una especie de venta forzosa al titular de los derechos, sobre todo en aquellos casos en los cuales este no habría estado dispuesto a otorgar la autorización al infractor. Ello en ningún caso implica sostener que la usurpación se legitima con el pago de la licencia; el infractor sigue siendo condenado por una conducta ilícita, y puede estar sujeto además a eventuales acciones indemnizatorias, como ya señalé, y por cierto responsabilidad penal. Pero como se puede apreciar, la licencia hipotética por sí sola no es disuasivo suficiente.

\section{Indemnización de daños morales}

El inciso tercero del artículo 85.E establece la posibilidad de solicitar la indemnización del daño moral, al señalar que "con independencia de la existencia de un perjuicio patrimonial, para efectos de la determinación del daño moral, el tribunal considerará las circunstancias de la infracción, la gravedad de la lesión, el menoscabo producido a la reputación del autor y el grado objetivo de difusión ilícita de la obra». Existiendo un trabajo que se refiere específicamente a esta materia (Barría Díaz, 2015), no me extenderé con detalle aquí sobre el asunto, aunque se apuntarán algunas precisiones.

El enunciado de la norma deja en claro que la existencia de daño patrimonial no condiciona de modo alguno la procedencia ni avaluación del daño moral, por lo que es perfectamente posible para el titular de los derechos solicitar la indemnización del daño moral con independencia de si existe o no daño patrimonial. La expresión «con independencia de la existencia de un perjuicio patrimonial» permite también reforzar la conclusión según la cual la indemnización del daño moral es acumulable no solo con la indemnización del daño patrimonial en efecto causado, sino también con el correspondiente al criterio de la licencia hipotética o valor de venta legítimo de los derechos. Por otra parte, la norma es interesante porque provee de criterios para la

21. Ello sin perjuicio de una eventual condena en costas, que podría operar como un factor disuasivo para el infractor. 
avaluación del daño moral, cuestión que no se establece en el derecho común chileno y que solo puede encontrarse en otras leyes especiales. ${ }^{22}$

En el derecho español, se ha planteado discutiblemente que la indemnización del daño moral en este ámbito podría tomar la forma de una indemnización punitiva al permitir a los tribunales aumentar las indemnizaciones patrimoniales cuando los daños efectivamente causados no son de suficiente magnitud (Carrasco Perera, 2007b: 1.701-1.702). Sin embargo, la mayoría de la doctrina rechaza esta interpretación, asignándole una naturaleza compensatoria a estas indemnizaciones (Rubí Puig, 2015: 673-675; Yzquierdo Tolsada y Arias Máiz, 2014: 1.659). Así también se ha entendido en Chile (Barría Díaz, 2015: 945). Parece ser correcta esta interpretación, en especial si se toma en cuenta que la norma se refiere a la «gravedad de la lesión» y no a la gravedad del ilícito para su avaluación. Todo lo anterior sin perjuicio de que, en la práctica, los tribunales de manera encubierta incorporen criterios retributivos para la avaluación del daño moral.

Otro aspecto objeto de controversia ha sido determinar qué tipo de daños morales quedan cubiertos por la norma. La doctrina española en su mayoría entiende que solo quedarían cubiertas las infracciones a derechos morales de autor (Carrasco Perera, 2007b: 1.669-1.670; Díez-Picazo, 1989: 1.698), esto es, aquellos derechos enumerados en el artículo 14 de la Ley de Propiedad Intelectual chilena. ${ }^{23}$ Esta posición también ha sido defendida entre nosotros (Barría Díaz, 2015: 947-948). Ello implicaría en primer lugar que quien quiera reclamar la indemnización de un daño moral no cubierto por el derecho moral de autor no podrá hacerlo recurriendo a esta norma, por lo que deberá acudir a las normas generales de la responsabilidad civil contractual o extracontractual. Así, por ejemplo, si la infracción cometida le causa un daño a la reputación del autor, la indemnización correspondiente a este daño no podría perseguirse invocando la Ley de Propiedad Intelectual, sino el artículo 2.314 o el artículo 2.329 del Código Civil. Desde luego, el hecho de que el Código Civil no contemple una norma que regule la procedencia ni avaluación del daño moral hace que esta interpretación no sea del todo atractiva. Además, para el titular del derecho ello traería el inconveniente de encontrarse obligado a demandar los perjuicios vía un procedimiento ordinario y no sumario. Ello resulta inadecuado no solo desde el punto de vista del titular de los derechos, sino también desde la perspectiva de la economía procesal.

22. Véase el artículo 41 de la Ley 19.966 de 2004.

23. La norma contempla los siguientes derechos: i) reivindicar la paternidad de la obra, asociando a la misma su nombre o seudónimo conocido; ii) oponerse a toda deformación, mutilación, u otra modificación hecha sin expreso y previo consentimiento - no se considerarán como tales los trabajos de conservación, reconstitución o restauración de las obras que hayan sufrido daños que alteren o menoscaben su valor artístico-; iii) mantener la obra inédita; iv) autorizar a terceros a terminar la obra inconclusa, previo consentimiento del editor o del cesionario si los hubiere; y v) exigir que se respete su voluntad de mantener la obra anónima o seudónima mientras ésta no pertenezca al patrimonio cultural común. 
A mi juicio, hay buenas razones para discrepar de esta interpretación para el ámbito del derecho chileno. En primer lugar, cabe señalar que esta postura no es unánime en el derecho español (Yzquierdo Tolsada y Arias Máiz, 2006: 86; 2014: 1.659). Por otra parte, la restricción de la indemnización del daño moral solo a los derechos morales de autor no es compartido en otras jurisdicciones como Alemania (Rubí Puig, 2015: 679). Sin embargo, la razón más poderosa para rechazar esta interpretación entre nosotros tiene que ver con la redacción de la norma, puesto que, a diferencia de la ley española, el artículo 85.E de la Ley de Propiedad Intelectual chilena menciona como criterio para la avaluación del daño moral «el menoscabo producido a la reputación del autor». Bajo la interpretación restrictiva, este criterio no tendría sentido, puesto que el daño a la reputación del autor no quedaría cubierto por la indemnización del daño moral; sin embargo, la ley lo menciona, lo cual da a entender que ella da por sentada o supone la indemnización por este tipo de daños, que no necesariamente coinciden con el derecho moral de autor descrito en el artículo 14. Por lo demás, cabe recordar el tradicional adagio «donde la ley no distingue, no le es lícito al intérprete distinguir».

Por último, cabe consignar que, siguiendo las reglas generales, el daño moral debe probarse (Domínguez Hidalgo, 2000: 716-718). ${ }^{24}$ En este ámbito, el titular de los derechos pierde el beneficio que le otorga la licencia hipotética de no tener que probar haber sufrido un daño. Ahora bien, como ocurre normalmente en la práctica, el daño moral sufrido por el titular de los derechos será probado mediante presunciones judiciales (Aedo Barrena, 2006: 505-506), por lo que los tribunales podrán, en la mayor parte de los casos, presumir la existencia de daño moral por el hecho de haberse cometido una infracción, bajo el principio de la res ipsa loquitor (Rubí Puig, 2015: 689).

Cabe señalar también que, para quienes la resarcibilidad del daño moral de autor se restringe a las infracciones del derecho moral, al titular de los derechos le bastaría con acreditar la infracción al derecho moral para probar la existencia de daño moral (Barría Díaz, 2015: 951-952). Ello nos parece correcto en la medida que se cometa una infracción al derecho moral de autor, sin aceptar necesariamente que dicha infracción sea la única posibilidad de solicitar daño moral en estos casos.

\section{La suma única compensatoria}

Por último, dadas las frecuentes dificultades de prueba que deben enfrentar los titulares de derechos de propiedad intelectual, el artículo 85.K de la Ley de Propiedad Intelectual establece que el titular puede solicitar al tribunal, «una vez acreditada

24. En este sentido, véase la sentencia de la Corte de Apelaciones de Santiago, rol 11.635-2016, de del 13 de marzo de 2018, en la que se acoge la demanda constatando la infracción, pero se rechaza el daño moral reclamado por falta de prueba del daño. 
judicialmente la respectiva infracción, que las indemnizaciones de los daños y perjuicios patrimoniales y morales causados sean sustituidas por una suma única compensatoria que será determinada por el tribunal en relación a la gravedad de la infracción, no pudiendo ser mayor a 2.000 unidades tributarias mensuales por infracción». Este mecanismo indemnizatorio fue incorporado por Chile el año 2010 como consecuencia de la suscripción del Tratado de Libre Comercio con Estados Unidos, con los llamados statutory damages estadounidenses como la principal influencia para la modificación (Walker Echenique, 2014: 328).

La norma establece que ello debe ser solicitado por el titular de los derechos. La Corte Suprema ha señalado que esta facultad puede ejercerla el demandante, una vez constatada la infracción para que se haga efectiva en la etapa de cumplimiento de la sentencia. ${ }^{25}$ Señala además la norma que esta cifra sustituye la indemnización de daños patrimoniales y morales, por lo cual ellos no podrán acumularse a esta suma indemnizatoria. Sin embargo, queda abierta la pregunta de si podría acumularse una restitución de ganancias, ya que se trata de una «suma única compensatoria». A mi juicio, los remedios no debieran acumularse, debido a que el artículo 85.E permite condenar al infractor a pagar las ganancias que haya obtenido "que no hayan sido consideradas al calcular los perjuicios». La discusión en cada caso se centrará en determinar si las ganancias obtenidas por el infractor fueron o no consideradas al momento que el juez determina la suma única compensatoria. Sin embargo, el antecedente del derecho norteamericano, del cual proviene el artículo 85.K, permite llegar a la misma conclusión, puesto que la norma del 17 USC $\$ 504$ (c), de donde proviene la norma, establece que la suma fijada por el juez reemplaza a los daños efectivamente sufridos y las ganancias. Sería deseable en cualquier caso que el legislador incluyera en una futura reforma una referencia expresa en la norma a las ganancias, para mayor claridad.

En cuanto a la determinación del monto, la norma le otorga discreción al tribunal, al establecer solo el límite máximo de 2.00o UTM, e indicando que el monto será determinado «en relación a la gravedad de la infracción». Podría resultar criticable el hecho de que la norma establezca como parámetro la gravedad de la infracción, si tenemos en cuenta que se trata de una suma única compensatoria. Así, pareciera ser que se trata más que de una indemnización, de una multa privada a favor del titular de los derechos. Dado el amplio carácter discrecional de su determinación, ello será difícilmente controlable vía recurso de casación en el fondo. Sin embargo, el tribunal deberá efectuar una determinación razonable para la determinación de este monto, al considerar factores como el grado de imputación subjetiva con que actuó el demandado, el grado de difusión que tuvo la reproducción ilícita de la obra, o el número de ventas efectuadas con infracción al derecho de propiedad infringido, entre otros factores.

25. Corte Suprema, rol 16.627-2016, 16 de mayo de 2017. 


\section{La acción de restitución de ganancias}

Especial interés para este estudio reviste la acción de restitución de las ganancias obtenidas de manera ilícita por el infractor, contemplada en el artículo 85.B inciso segundo de la Ley de Propiedad Intelectual. La disposición señala que «el tribunal podrá, además, condenar al infractor a pagar las ganancias que haya obtenido, que sean atribuibles a la infracción y que no hayan sido consideradas al calcular los perjuicios». La norma está inspirada, al igual que en el caso del artículo 85.K, en el derecho norteamericano. La norma fue trasplantada casi en forma literal de la regla estadounidense 17 USC $\$ 504(b)$, aunque esta última agrega que al titular de los derechos le bastará con acreditar las ganancias obtenidas por el infractor en bruto, mientras que es carga del demandado acreditar la existencia de gastos y otros montos que pudieran deducirse del monto bruto.

Respecto de la naturaleza jurídica de esta acción, la doctrina chilena ya se ha pronunciado a favor de atribuirle una naturaleza jurídica restitutoria y no indemnizatoria, ello a pesar del tenor literal de la norma que pudiera todavía sugerir que se trata de una acción indemnizatoria (Barría Díaz, 2017a: 201; 2017b: 405; Corral Talciani, 2013: 336). La conclusión de estos autores es correcta, debido a que se trata de una hipótesis de restitución de ganancias, en la cual la procedencia y la medida del remedio no dependen de la existencia y extensión de algún daño en efecto causado al titular de los derechos, sino de beneficios o ganancias obtenidas por el demandado mediante la infracción del derecho (Basozabal Arrué, 1998: 38-39; Pino Emhart, 2016: 239-241). Ahora bien, la norma dispone que el tribunal podrá, además, condenar al infractor a la restitución de las ganancias, lo cual es bastante peculiar desde el punto de vista de los supuestos de restitución de ganancias ilícitas.

En primer lugar, por lo general las acciones restitutorias no quedan sujetas a la discreción del tribunal, sino que suelen considerarse como una opción para el demandante. Es el caso paradigmático de la triple opción contemplada en el artículo 108 de la Ley de Propiedad Industrial chilena, que establece como opción para el demandante la indemnización de perjuicios según las reglas generales (letra a), la restitución de los beneficios obtenidos como consecuencia de la infracción (letra b), y el precio que el infractor hubiera debido pagar al titular del derecho por el otorgamiento de una licencia (letra c). En el ámbito de la propiedad industrial, la opción es del demandante. En cambio, el artículo 85.B establece un ámbito de discrecionalidad para el tribunal. Sobre este punto, cabe destacar que la norma no señala que el tribunal deberá actuar «a petición de parte», como sí lo hace en otras disposiciones de la Ley de Propiedad Intelectual, como la del artículo 85.K. Por consiguiente, es plausible concluir que la norma permite actuar de oficio al tribunal, facultando a este 
para condenar a la restitución de ganancias en los casos que estime conveniente. ${ }^{26}$ Por cierto que debe determinarse en qué casos ello sería procedente. Más adelante nos referiremos a esto.

La segunda característica peculiar de la norma es la (eventual) posibilidad que otorga de acumular la restitución de ganancias con las acciones indemnizatorias. Ello nuevamente contrasta con el ámbito de la propiedad industrial, donde el demandante necesariamente debe escoger una de las tres opciones que dispone la ley. En cambio, el artículo 85.B de la LPI establece que la restitución de ganancias es adicional a la indemnización de perjuicios («podrá además»), aunque se establece una incompatibilidad de carácter sustantivo entre las acciones, al señalarse que se restituirán aquellos beneficios que no hayan sido considerados al calcular el monto de los perjuicios. Como ya he indicado, se trata de un trasplante literal del derecho norteamericano, en el cual se reconoce efectivamente que la restitución de ganancias procede adicionalmente a la indemnización de los perjuicios efectivamente sufridos, siempre y cuando ello no implique un doble pago para el demandante (Ross, 2018: 672). La decisión del legislador chileno de adoptar este criterio es discutible, puesto que otros ordenamientos contemplan la restitución de ganancias como un mecanismo alternativo a la indemnización de perjuicios, de manera similar a la triple opción de la propiedad industrial. Así, por ejemplo, en el derecho inglés se establece que el demandante debe elegir entre la restitución de ganancias o la indemnización de perjuicios (Bently y otros, 2018: 1347-138; Speck, 2018: 1232). En tanto, en el derecho alemán la legislación de derechos de autor solo contempla remedios restitutorios por la vía de las licencias hipotéticas, aunque gran parte de la doctrina plantea la procedencia de restitución de ganancias si la infracción se comete dolosamente o en forma deliberada, en virtud de la figura de negotiorum gestio (Krebs, 2006: 387; Schlechtriem, 2007: 65).

Corresponde entonces analizar en qué consiste la incompatibilidad sustantiva contemplada por la norma entre la restitución de ganancias y la indemnización de perjuicios. Barría Díaz (2017b: 407-408) correctamente señala que el sentido de la norma es evitar que en el cálculo de las ganancias a restituir se consideren las partidas que ya fueron consideradas a título de lucro cesante, ya sea que se consideren como daños efectivamente sufridos o a través del valor de venta legítimo. Como ya se advirtió, el criterio del valor de venta legítimo no considera las ganancias efectivamente obtenidas por el infractor, sino tan solo considera el valor que el demandado habría tenido que pagar al demandante si hubiese solicitado autorización en forma previa. Así, por ejemplo, supongamos una constructora que utiliza planos de un conocido arquitecto sin su autorización para construir un centro comercial. El valor de venta legítimo de los planos debiera determinarse sobre la base del precio de mercado de los derechos, por ejemplo, recurriendo a diseños anteriores del mismo arquitecto, $\mathrm{o}$

26. En contra, Barría Díaz (2017a: 203), aunque no argumenta específicamente sobre el punto. 
algún otro arquitecto de prestigio similar. Supongamos que este precio de licencia hipotética asciende a $\$ 10$ millones. Este valor no considera las utilidades que la constructora ha obtenido como consecuencia de la construcción del centro comercial. Si el tribunal estima procedente un remedio adicional de restitución de ganancias, debiera considerar las utilidades obtenidas por la constructora utilizando los planos sin la debida autorización. Supongamos que las utilidades ascienden a \$10o millones. En tal caso, de ese monto a restituir debieran descontarse los $\$ 10$ millones de pesos asignados a modo de licencia hipotética, pues de lo contrario se estaría efectuando un doble pago.

Ahora bien, como puede apreciarse en el ejemplo anterior, la restitución de ganancias puede ser considerada un remedio altamente represivo, que puede resultar en montos muy superiores al monto de los daños efectivamente causados. Como advierte Barría Díaz (2017b: 408), ello puede conducir al riesgo de estimar que el remedio sea considerado desproporcionado en relación con la infracción cometida, lo que incluso podría acarrear cuestionamientos constitucionales. ${ }^{27}$ Sin embargo, para poder hacer un juicio de proporcionalidad del remedio, la pregunta que cabe plantearse es: ¿proporcionalidad respecto a qué? Desde luego el criterio de la proporcionalidad no puede encontrarse determinado sobre la base de una comparación con algún daño si lo hubiere- efectivamente sufrido, porque aquí se trata de restituir beneficios y no compensar daños. Por otra parte, al analizar si se trata de una medida proporcionada en relación con la infracción, en particular en cuanto a determinar si existe alguna medida menos coercitiva para lograr el mismo objetivo, el remedio pareciera justificarse sobre la base de los criterios de disuasión apuntados más arriba, lo que permite suplir las deficiencias del criterio de las regalías hipotéticas para prevenir este tipo de infracciones. Desde este punto de vista, si bien el remedio resulta más restrictivo de la libertad que las licencias o regalías hipotéticas, lo cierto es que el legislador ha confiado en la restitución de ganancias ilícitas como la principal herramienta disuasiva, ya que no se incorporó a la legislación chilena las indemnizaciones punitivas (statutory damages) contempladas por la legislación norteamericana 17 USC $\$ 504$ (c)(2) que la Ley de Propiedad Intelectual chilena sigue de cerca. De manera tal que bien podría considerarse la restitución de ganancias ilícitas como un remedio que reemplaza las indemnizaciones punitivas, al ser menos coercitivas y problemáticas para los sistemas de tradición civil continental (Kemelmajer de Carlucci, 1993: 71).

Como ya se ha indicado, el artículo 85.E le otorga una facultad discrecional al juez para decretar la restitución de ganancias, utilizando la expresión "podrá». Sostengo que esta discrecionalidad del juez puede modularse considerando el grado de imputación subjetiva atribuible al infractor. Lo anterior no se desprende del texto

27. Sobre los mismos cuestionamientos constitucionales sometidos a conocimiento del Tribunal Constitucional en el ámbito de la propiedad industrial, véase Pino Emhart (2015). 
de la norma, pero es una interpretación plausible en atención a los fundamentos de la acción y los antecedentes del derecho comparado. Ya se advirtió más arriba que sistemas como el derecho alemán y el derecho inglés condicionan la restitución de ganancias a la satisfacción de un requisito de intencionalidad del infractor. Si bien es efectivo que el principal antecedente del artículo 85.E de la Ley de Propiedad Intelectual, el $\$ 504$ (b) de la ley norteamericana, no contiene este requisito, lo cierto es que el derecho norteamericano contempla indemnizaciones punitivas a título de statutory damages, reservados solo para infracciones cometidas de manera intencional (willfully) (17 USC $\$ 504(c)(2)$ ). La legislación chilena no contempla esta agravación de las indemnizaciones, función que de alguna manera sustitutiva es desempeñada por la restitución de ganancias. De modo tal que es plausible sostener que el tribunal ordene la restitución de ganancias solo en aquellos casos de infracciones dolosas o intencionales, excluyendo infracciones meramente negligentes. ${ }^{28}$ Ello además se ve reforzado tomando en cuenta el objetivo disuasivo del remedio, puesto que la disuasión solo se justifica en la medida que se trate de una infracción intencional, dolosa o calculada. A mi juicio, esta es la mejor forma de interpretar la expresión «podrá» empleada por la norma chilena, y que no se encuentra presente en la legislación norteamericana, la cual se limita a señalar que el titular de los derechos de autor tiene derecho a demandar las ganancias obtenidas por el infractor (17 U.S.C. \$ 504(b)).

Por otra parte, debe recordarse que la norma del artículo 85.E permite al tribunal ordenar la restitución de las ganancias «que sean atribuibles a la infracción». Por consiguiente, el tribunal deberá determinar cuáles son aquellas ganancias que pueden ser causalmente atribuidas a la infracción. De ello se siguen, a mi juicio, dos consecuencias. En primer lugar, debieran descartarse aquellas ganancias que no tengan una relación directa con la infracción, sino solo una relación remota. ${ }^{29}$ Por cierto, no se trata de una labor sencilla (Blair y Cotter, 1998: 1.652). Pero en el ejemplo anterior del diseño para un centro comercial, supongamos ahora que producto de la exitosa construcción del centro comercial, el contratista decide encargarle a la constructora una ampliación del diseño anterior que le generará mayores utilidades. Si bien la infracción a la propiedad intelectual del arquitecto fue causa necesaria de estas ganancias, no es una causa directa, sino remota de ellas. Por ello es que debiesen estar excluidas.

En segundo lugar, también debiese permitirse la posibilidad para el demandado de descontar del monto a restituir los gastos y esfuerzos propios razonables en que haya incurrido el demandado para generar dichas ganancias. Si bien esta eventual defensa para el demandado no se encuentra en el texto del artículo 85.E, ello se desprende del requisito de causalidad y también del principio general del enriquecimiento

28. En contra, Barría Díaz (2017b: 416).

29. Restatement of the Law (Third) Restitution and Unjust Enrichment, American Law Institute, 2011, $\$ 51$, comentario $\mathrm{f}$. 
injustificado. Desde el punto de vista causal, si el demandado incurrió en gastos e hizo esfuerzos propios para obtener las ganancias, ello implicaría que en alguna medida estas ganancias ya no fueron causadas por el incumplimiento del deber. Por otra parte, desde el punto de vista del enriquecimiento injustificado, de no descontarse estos gastos y esfuerzos del demandado, se estaría generando un enriquecimiento injustificado para el demandante al beneficiarse del trabajo o los gastos invertidos por el demandado, en una especie de agencia oficiosa. En el ejemplo anterior de los planos para un centro comercial, sería razonable descontar de los beneficios a reembolsar mediante la acción, aquellos gastos en que haya incurrido la constructora, por lo que debería en consecuencia pagar solo las utilidades netas obtenidas. Por cierto, será carga del demandado demostrar la existencia de estos eventuales descuentos, mientras que sería suficiente para el titular de los derechos demostrar la existencia de utilidades en bruto (17 USC $\$ 504(b))$.

\section{Conclusiones}

Como se ha visto, el legislador chileno pone a disposición del titular de los derechos de propiedad intelectual un complejo abanico de acciones para la protección de sus derechos. Dada la naturaleza propietaria de estos derechos, la Ley de Propiedad Intelectual dispone de mecanismos de reparación en naturaleza que pueden ser en particular relevantes para el titular de los derechos, y que prescinden de la acreditación de un daño o de beneficios obtenidos por el infractor, por lo que es suficiente que se acredite la infracción. Sobre esta materia, la regulación chilena es un tanto deficiente, por cuanto carece de los criterios flexibles que normalmente se establecen para el otorgamiento de estas medidas.

En cuanto a la acción indemnizatoria, se han destacado las características del mecanismo restitutorio de las licencias o regalías hipotéticas, que permiten liberar al titular de los derechos de la carga gravosa de demostrar la existencia de daños efectivamente sufridos, aunque reconociendo sus deficiencias en tanto dispositivo destinado a la prevención de infracciones al derecho de propiedad intelectual. Respecto del daño moral, se propone una interpretación amplia, que abarque no solo el derecho moral de autor, sino también el daño extrapatrimonial en términos generales. Se sostiene que la indemnización del daño moral es perfectamente acumulable con las demás partidas indemnizatorias, incluyendo las licencias hipotéticas.

Respecto de la acción de restitución de ganancias, se sostiene que el principal fundamento del mecanismo es la disuasión, lo que suple las deficiencias ya mencionadas de la acción indemnizatoria y las licencias hipotéticas. Sobre esta materia, la legislación chilena sigue muy de cerca la legislación norteamericana. El artículo 85.E establece una restricción de doble pago, que limita la restitución de ganancias a aquéllas que no hayan sido consideradas al calcular los perjuicios. Se ha argumentado que 
esta restricción solo debiera extenderse a la indemnización del lucro cesante o las licencias hipotéticas que hubieren sido decretadas por el tribunal. Además, se plantea que la expresión «podrá», utilizada por la norma, le otorga discrecionalidad al juez para decretar el remedio, y dicha discreción debiera regularse sobre la base del grado de intencionalidad con la cual actuó el demandado al cometer la infracción.

No cabe duda de que cada uno de estos mecanismos merece un mayor estudio en detalle de lo que se ha podido hacer aquí. Es en particular atingente en este sentido revisar la acogida por parte de los tribunales chilenos de estas normas relativamente recientes, tarea que escapa a los propósitos de este trabajo. La tendencia general en el ámbito de la responsabilidad civil es a centrarse en los elementos generales de la responsabilidad, desatendiendo el estudio acabado de los remedios que la legislación pone a disposición del titular de los derechos. Muchos de estos problemas, que en ocasiones pueden encuadrarse dentro de la disciplina del derecho procesal, dicen relación con aspectos sustantivos de los derechos protegidos, ya que para hacer valer sus derechos el titular requiere la existencia de mecanismos adecuados para su protección. En este sentido, queda abierto a discusión si los mecanismos contemplados por la actual Ley de Propiedad Intelectual chilena otorgan en efecto mecanismos suficientemente eficaces para la protección de estos derechos.

\section{Agradecimientos}

Este trabajo presenta resultados del proyecto Fondecyt de iniciación núm. 11170398, titulado: «La restitución de ganancias ilícitas en el derecho privado chileno», del que el autor es investigador responsable. El autor agradece al Instituto Max Planck de derecho privado en Hamburgo por el generoso acceso a su biblioteca y recursos bibliográficos.

\section{Referencias}

Aedo Barrena, Cristián (2006). Responsabilidad extracontractual. Santiago: Librotecnia.

Armengot Vilaplana, Alicia (2003). La tutela judicial civil de la propiedad intelectual. Madrid: La Ley.

BAHAmondes Oyarzún, Claudia (2018). «La ejecución personal como límite al cumplimiento específico del contrato: Un acercamiento a partir de los derechos fundamentales del deudor». En Claudia Bahamondes Oyarzún, Leonor Etcheberry Court y Carlos Pizarro Wilson (editores), Estudios de derecho civil 13. Santiago: Thomson Reuters.

BARRía DíAz, Rodrigo (2015): «Configuración del daño moral de autor en la Ley de Propiedad Intelectual». En Álvaro Vidal Olivares (editor), Estudios de derecho civil 10. Santiago de Chile: Thomson Reuters. 
-. (2017a): «La acción de enriquecimiento injustificado por la intromisión en los derechos de propiedad intelectual». En Hernán Corral Talciani y Pablo Manterola Domínguez (editores), Estudios de derecho civil 12. Santiago: Thomson Reuters.

-. (2017b): «La función preventiva o disuasoria de la responsabilidad civil, a propósito de las Leyes de Propiedad Intelectual y de Propiedad Industrial». En Alfredo Ferrante, Lilian San Martín Neira y Rodrigo Barría Díaz (editores), Presente y futuro de la responsabilidad civil. Santiago: Thomson Reuters.

Barros Bourie, Enrique (2006). Tratado de responsabilidad civil extracontractual. Santiago: Jurídica de Chile.

-. (2009). «Restitución de ganancias por intromisión en derecho ajeno por incumplimiento contractual y por ilícito extracontractual». En Enrique Barros Bourie, M. Paz García Rubio y Antonio M. Morales Moreno, Derecho de daños. Madrid: Fundación Coloquio Jurídico Europeo.

Basozabal Arrué, Xabier (1997). «Método triple de cómputo del daño: La indemnización del lucro cesante en las leyes de protección industrial e intelectual». Anuario de Derecho Civil, 50 (3): 1.263-1.300.

-. (1998). Enriquecimiento injustificado por intromisión en derecho ajeno. Madrid: Civitas.

Bently, Lionel, Brad Sherman, Dev Gangjee y Phillip Johnson (2018). Intellectual property. 5. ${ }^{\text {a }}$ edición. Oxford: Oxford University Press.

BlaIR, Roger y Thomas Cotter (1998). "An economic analysis of damages rules in intellectual property». William \& Mary Law Review, 39(5): 1.585-1.694. Disponible en https://bit.ly/36qN6le.

Burrows, Andrew (2007). «Judicial remedies». En Andrew Burrows (editor), English Private Law. Oxford: Oxford University Press.

-. (2008). "Are damages on the Wrotham Park Basis' compensatory, restitutionary or neither?». En Djakhongir Saidov y Ralph Cunnington (editores), Contract damages: Domestic and international perspectives. Oxford: Hart Publishing.

Calabresi, Guido y Douglas Melamed (1996). «Reglas de propiedad, reglas de responsabilidad y de inalienabilidad: Una vista de la catedral». Estudios Públicos, 63: 347-391. Disponible en http://bit.ly/2PCW743.

Cárdenas Villarreal, Hugo y Ricardo Reveco Urzúa (2018). Remedios contractuales. Santiago: Thomson Reuters.

Carrasco Perera, Ángel (2007a). «Acciones y medidas cautelares urgentes». En Rodrigo Bercovitz Rodríguez-Cano (coordinador), Comentarios a la Ley de Propiedad Intelectual. 3. ${ }^{a}$ edición. Madrid: Tecnos.

-. (2007b). «Indemnización». En Rodrigo Bercovitz Rodríguez-Cano (coordinador), Comentarios a la Ley de Propiedad Intelectual. $3 .^{\text {a }}$ edición. Madrid: Tecnos.

Cerda Silva, Alberto J. (2016). «Evolución histórica del derecho de autor en América Latina». Ius et Praxis, 22 (1): 19-58. DOI: 10.4067/So718-00122016000100002. 
Contreras-Jaramillo, Juan Camilo (2017). «El aparato teórico en la estructura tradicional del sistema de propiedad intelectual». Vniversitas, 135: 99-130. DOI: 10.11144/Javeriana.vj135.atet.

Corral TAlCiani, Hernán (2013). Lecciones de responsabilidad extracontractual. 2. ${ }^{\mathrm{a}}$ edición. Santiago: Legal Publishing.

De la MazA, Íñigo y Álvaro Vidal Olivares (2018). Cuestiones de derecho de contratos. Santiago: Thomson Reuters.

DíEz-Picazo, Luis (1989). «Comentario al artículo 125». En Rodrigo Bercovitz Rodríguez-Cano (coordinador), Comentarios a la Ley de Propiedad Intelectual. 1. ${ }^{\mathrm{a}}$ edición. Madrid: Tecnos.

Domínguez Hidalgo, Carmen (200o). El daño moral. Santiago: Jurídica de Chile.

EDELMAN, James (2010). "The measure of restitution and the future of restitutionary damages». Restitution Law Review, 18: 1-13.

ENGLARD, Izhak (2007). «Restitution of benefits conferred without obligation». En Ernst von Caemmerer y Peter Schlechtriem (editores), International encyclopedia of Comparative Law. Volumen 10. Tubinga: Mohr Siebeck.

Epstein, Richard A. (2018). «The basic structure of Intellectual Property Law». En Rochelle C. Dreyfuss y Justine Pila (editores), The Oxford handbook of Intellectual Property Law. Oxford: Oxford University Press.

GuZMÁn BRITO, Alejandro (1995). Las cosas incorporales en la doctrina y en el derecho positivo. Santiago: Jurídica de Chile.

Hedley, Steve (2001). A critical introduction to restitution. Londres: Butterworths.

JAFFEY, Peter (2000). The nature and scope of restitution. Oxford: Hart.

-. (2011). «Licence fee damages». Restitution Law Review, 19: 95-111.

Kemelmajer de Carlucci, Aída (1993). «¿Conviene la introducción de los llamados daños punitivos en el derecho argentino?». Separata de la Academia Nacional de Derecho y Ciencias Sociales de Buenos Aires, 38: 24-135.

Krebs, Thomas (2006). "The fallacy of "restitution for wrongs"». En Andrew Burrows (editor), Mapping the law: Essays in memory of Peter Birks. Oxford: Oxford University Press.

LODDER, Andrew V. M. (2012). Enrichment in the law of unjust enrichment and restitution. Oxford: Hart.

Morales ANDrade, Marcos (2006). «Elementos de responsabilidad extracontractual en materia de marcas comerciales». En Marcos Morales Andrade (editor), Temas actuales de propiedad intelectual: Estudios en homenaje a la memoria del profesor Santiago Larraguibel Zavala. Santiago: Lexis Nexis.

PeÑaIlillo Arévalo, Daniel (2003). Obligaciones: Teoría general y clasificaciones. La resolución por incumplimiento. Santiago: Jurídica de Chile.

PIno Emhart, Alberto (2016). «La restitución de ganancias y la acción de provecho por dolo ajeno». Ius et Praxis, 22(1): 227-270. DOI: 10.4067/So718-00122016000100008. 
-. (2019). «Las acciones civiles por infracciones al derecho de propiedad industrial». En Manuel Barría Paredes (coordinador), Estudios de derecho patrimonial en homenaje al profesor Daniel Peñailillo Arévalo. Santiago: Thomson Reuters.

Rivero Hurtado, Renée Marlene (2019). «La tutela meramente declarativa o de mera certeza y su reconocimiento en el sistema procesal civil chileno». Ius et Praxis, 25 (1): 89-130. DOI: 10.4067/So718-00122019000100089.

Ross, Terrence P. (2018). «Remedies». En Rochelle C. Dreyfuss y Justine Pila, The Oxford handbook of Intellectual Property Law. Oxford: Oxford University Press.

Rubí Puig, Antoni (2015). «Daño moral por infracción de derechos de propiedad intelectual o industrial». En Fernando Gómez Pomar e Ignacio Marín García (directores), El daño moral y su cuantificación. Barcelona: Bosch.

Schlechtriem, Peter (2007). «Unjust enrichment by interference with property rights». En Ernst von Caemmerer y Peter Schlechtriem (editores), International encyclopedia of Comparative Law. Volumen 10. Tubinga: Mohr Siebeck.

Sharpe, Robert J. y S. M. Waddams (1982). «Damages for lost opportunity to bargain». Oxford Journal of Legal Studies, 2(2): 290-297. DOI: 10.1093/ojls/2.2.290.

SikorsKi, Rafal (2019). «Patent injunctions in the European Union Law». En Rafal Sikorski (editor), Patent law injunctions. Alphen aan den Rijn: Kluwer Law.

Speck, Adrian, Hugh Ian Lang Laddie, Lindsay Lane, Peter Prescott, Daniel Alexander, Mary Vitoria, Michael Tappin, Charlotte May y Iona Berkeley (2018). The modern Law of Copyright. Croyton: Lexis Nexis.

Ströмноlм, Stig (1990). «Copyright: Comparison of Laws». En Eugen Ulmer y Gerhard Schricker (editores), International encyclopedia of Comparative Law. Volumen 14. Tubinga: Mohr Siebeck.

WALdron, Jeremy (1996). «Property Law». En Dennis Patterson (editor), A Companion to philosophy of law and legal theory. Oxford: Blackwell.

Walker Echenique, Elisa (2014). Manual de propiedad intelectual. Santiago: Thomson Reuters.

Yzquierdo Tolsada, Mariano y Vicente Arias Máiz (2006). Daños y perjuicios en la propiedad intelectual. Madrid: Fundación Arte y Derecho.

-. (2014). «Responsabilidad civil por daños a la propiedad intelectual». En L. Fernando Reglero Campos y José Manuel Busto Lago (coordinadores), Tratado de responsabilidad civil. 5 . $^{\text {a }}$ edición. Navarra: Aranzadi.

\section{Sobre el autor}

Alberto Pino Emhart es abogado. Doctor en Derecho de la Universidad de Oxford, Reino Unido. Profesor asistente de la Universidad Adolfo Ibáñez, Chile. Su correo electrónico es alberto.pino@uai.cl. (D) http://orcid.org/oooo-0o03-2066-6611. 


\title{
REVISTA CHILENA DE DERECHO Y TECNOLOGÍA
}

La Revista de Chilena de Derecho y Tecnología es una publicación académica semestral del Centro de Estudios en Derecho Informático de la Facultad de Derecho de la Universidad de Chile, que tiene por objeto difundir en la comunidad jurídica los elementos necesarios para analizar y comprender los alcances y efectos que el desarrollo tecnológico y cultural han producido en la sociedad, especialmente su impacto en la ciencia jurídica.

\author{
EDITOR GENERAL \\ Daniel Álvarez Valenzuela \\ (dalvarez@derecho.uchile.cl) \\ SITIO WEB \\ rchdt.uchile.cl \\ CORREO ELECTRÓNICO \\ rchdt@derecho.uchile.cl \\ LICENCIA DE ESTE ARTÍ́CULO \\ Creative Commons Atribución Compartir Igual 4.o Internacional
}

\begin{abstract}
La edición de textos, el diseño editorial
y la conversión a formatos electrónicos de este artículo

estuvieron a cargo de Tipográfica

(www.tipografica.cl).
\end{abstract}

